\title{
Implementing Competency-based Education
}

COLLECTED ESSAT

ON LEARNING

2017 CELT Vol X

celt.uwindsor.ca

www.stlhe.ca

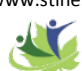

STLHE SAPES

Lynn Curry, CurryCorp, Inc. Marcia Docherty, Camosun College

DOI: $10.22329 /$ celt.v10i0.4716

The rapid and widespread adoption of competency-based education (CBE) has brought into sharp focus long-standing tensions built into education systems, particularly for graduate and professional schools. We all share the desire to produce graduates equipped to respond capably in a rapidly changing world. However, many of us struggle with the knowledge, skills, and attitudes required to identify, articulate, deliver, document, assess, assure, and adjust those necessary competencies across learning engagements, work-study experiences, and into work careers. CBE forces us to alter familiar pedagogical beliefs, attitudes, and behaviours. The purpose of this essay is to assist faculty, students, administrators, regulators, and employers in considering the strengths and limitations of competencebased education (CBE). We also introduce a range of mitigating strategies to address $C B E$ shortcomings.

$\mathrm{E}^{\mathrm{s}}$ veryone involved in any educational enterprise shares the desire that graduates be equipped to respond capably in a rapidly changing world. Competency-based (or outcomes-based) education (CBE) is an educational model organized to realize these aims by beginning with definitions of desired endpoints. This approach has a 100-year developmental history beginning in the workplace efficiency movement (Tayler, 1911) and moving to education by the 1940's (Tyler, 1949). Interest waxed and waned cyclically over ensuing years with $\mathrm{CBE}$ currently enjoying global support at all educational levels from government and policy organizations such as the US Department of Education (US Department of Education, n.d.), the Conference Board of Canada (2009), and the Organisation for Economic Cooperation and Development (Tremblay, Lalancette, Roseveare, 2012). Although there is a large published literature describing $\mathrm{CBE}$, there is not much evidence of improved learning effectiveness (Carraccio, Wolfsthal, Englander, Ferentz, \& Martin, 2002; Malone \& Supri, 2012; Morcke, Dornan, \& Eika, 2013), and even less about implementing CBE successfully.
The purpose of this essay is to orient participants-be these, faculty, students, administrators, regulators, and employers-around critical concepts required to operationalize competency-based approaches in their spheres of responsibility and, equally important, to mitigate CBE limitations. We make no argument for or against $\mathrm{CBE}$ approaches; there are after all many ways to produce capable graduates. We focus on the practicalities of making CBE work. The essay will not dwell on historical development or conceptual evolution. These are worthy topics and have been addressed in the available literature. Furthermore, throughout this essay we purposefully conflate outcomes-based and competency-based education. These educational models differ in details but share a central tenet that the content of the educational experience should be derived from pre-specified exit expectations. Referring to these endpoint expectations as "outcomes" is more common within general and foundational educational levels whereas technical and professional schools have a social contract to define and provide relevant "competencies" related to adequate professional performance. There is extensive literature on both 
outcomes-based and competency-based models, and on their subtle differences (Albanese, Mejicano, Mullan, Kokotailo, \& Gruppen, 2008).

Our focus in this essay is the gap between intention to orient curricula towards desired endpoint expectations and making that happen in real time. We address participants seeking an approach to identify, articulate, deliver, document, assess, assure, and adjust necessary competencies across prior learning, alternative learning engagements, workstudy experiences, and into work careers.

An essay is not a workbook. We present no detailed operational plans or specific solution steps. That level of detail is ultimately not helpful because specific contexts, constraints, and opportunities play a large role at the level of local innovation and implementation. Our intention is to outline the minimum conceptual set and provide generalized guidance on practical approaches in each of the critical areas. Illustrations will be primarily drawn from higher and professions education only because the need for effective CBE operationalization in these settings is presently accentuated due to accreditation mandates and frank competition for student dollars.

\section{CBE: What is It?}

Educational structures characterized as competencyor outcome-based can be identified by various manifestations of functioning end points: educational objectives, outcomes statements, competency frameworks, task analyses, employability skills lists, performance and grading checklists. What is common across these tactics is the focus on endpoint behavioural competence and therefore on assessing direct indications of attained competence throughout the educational experience. This focus contrasts with the still common assumption that competence is related to time in courses or service. Similarly, the CBE approach removes the emphasis on institutional reputation as a proxy for graduate quality. In CBE both assumptions are replaced with documentation of classroom, simulation, and work execution indicators chosen to reflect demands of the next placement or workplace performance.

\section{CBE: Historical development}

CBE has its origins in Taylor's (1911) behaviour focused approach to performance improvement in the workplace. At the same time, educational movements for social efficiency and essentialism were calling for educational practices that were efficient, effective, and standardized (Schilling \& Koetting, 2010). Principles from Taylor's scientific management were applied to compartmentalize, sequence, and streamline classroom learning; competency standards were applied to students, and teacher preparation focused on efficient instructional delivery relevant to those competency standards (Schilling \& Koetting, 2010; Tuxworth, 1994). By the late 1960s, the US Office of Education formalized the competency-based approach as a direct measure of student learning (Tuxworth, 1994).

By the early 1970's similar expectations had migrated to higher education. McClelland (1973) argued that higher education must move beyond institutional reputation as an indicator of graduate competence towards a competency-based approach reflective of workplace needs. This movement is still in place today as supported by organizations such as the Council for Aid to Education (Council for Aid to Education, n.d.) and the Organisation for Economic Co-operation and Development (Tremblay et al., 2012) that, respectively, set national and international standards for higher education outcomes.

While CBE has been used to varying degrees in professional, trade, and military training for decades, the medical discipline has recently espoused $\mathrm{CBE}$ at an international level. Heralded as a paradigm shift towards safer and higher quality healthcare (Carraccio et al., 2002; Long, 2000), CBE is now a requirement for graduate medical program accreditation in North America (Accreditation Council for Graduate Medical Education [ACGME], 2016). The medical field defines $C B E$ as:

an approach to preparing physicians for practice that is fundamentally oriented to graduate outcome abilities and organized around competencies derived from an analysis of societal and patient needs. It de- 
emphasizes time-based training and promises greater accountability, flexibility, and learner-centredness (Frank et al., 2010, p. 636).

\section{Expectations for CBE}

Authors and agencies endorsing CBE have high expectations of efficacy. Real-world relevance, marketability, increased mobility, and intrinsic motivation for students, graduates, and faculty development have all been indicated as objectives for reorganizing educational structures to follow the $\mathrm{CBE}$ model. Collaboration across and within different types, contexts, and venues for education should also be easier to initiate and support under CBE structures. Properly organized, CBE could provide a basis for flexible, authentic, learning and assessment activities while de-emphasizing time- and situationbased proxies for learning.

These aspirations are rarely achieved in practice for a range of reasons: the measurement of competence is not well understood (Blömeke, Zlatkin-Troitshcanskaia, Kuhn, \& Fege, 2013); questionable competence identification validity (Shippmann et al., 2000); definitional weakness in affective domains (Fish \& de Cossart, 2006; Taylor, Irvine, Bradbury-Jones, \& McKenna, 2010); lack of faculty training (Calhoun, Wrobel, \& Finnegan, 2011); and lack of institutional flexibility and accommodation (Iobst et al., 2010). Furthermore, many critics complain that the granularity of $\mathrm{CBE}$ entirely misses the complex selection and coordination of competencies required for proficient practice in real-world situations (Fish \& de Cossart, 2006; Talbot, 2004). Recent reviews (Touchie \& ten Cate, 2016; Morcke et al., 2013) suggest that for many CBE programs and participants there is still a significant gulf between embracing the concept of
$\mathrm{CBE}$ and achieving functional applications, let alone realizing desired results.

\section{Conceptual Limitations of CBE}

CBE limitations are not widely acknowledged nor their ramifications understood. Based as it is in behaviourism, CBE measures only observable results, ignoring the complex connections across thought, performance, and context. CBE assumes that all competencies can be reduced to statements of observed performance (Lum, 1999; Morcke et al., 2013), that there is a single, preferred pathway to competency attainment (Delaney, Carslon-Sabelli, Shephard, \& Ridge, 2011), and that observers or raters are always objective (Govaerts, van der Vleuten, Schuwirth, \& Muijtjens, 2007). It is further assumed that correct performance is a result of correct thought/knowledge and will unfailingly produce desired results in all situations. Humanistic competencies such as accountability, altruism, curiosity, empathy, and innovation are not easily reduced to functional indicators as required by CBE (Hodges, 2010). Competencies are stated in terms of minimally acceptable performance, which promotes settling for "good enough" in direct contradiction to professional expectations of excellence (Talbot, 2004).

CBE rationales (Cooke, Irby, \& O'Brien, 2010) tend to ignore the realities of teaching and learning in favor of accountability and assessment. In increasing competitive educational settings, methods that provide accountability for resources used, and outputs obtained, are appealing in their potential to reduce costs and training time. This improved output function (specified outcomes; cheaper throughput) is achieved through standardization, which does not fit well with the known reality of widely variable learners, teachers, and application settings. 


\section{Educational Design, Teaching, and Learning with $\mathrm{CBE}$}

The defining strength of $\mathrm{CBE}$ is the attention to outcome competencies. From those product competencies, a full range of supporting learning goals must be articulated, ordered, and located within educational programs, individual courses, and sequences of learning experience. When learning goals and outcomes are clear and well organized, a conceptual scaffold is created for the work of teachers and learners (Morcke et al., 2013; Spady, 1994). Such goal-orientation can be used as a rubric to sort, understand and modify how each course or experience connects to a larger program of study, personalized learning needs, and requirements of the next placement or eventual workplace. This connection clarity allows educational program evaluation to examine all the supporting structures of curricula, teaching, learning activity, assessment, and feedback to confirm alignment to desired goals and outcomes.

Commitment to $\mathrm{CBE}$, therefore, means examining in detail how we design, teach, assess, and learn within CBE structured educational programs. A thorough, systematic, sustained, and integrated approach is required to improve learner outcomes by streamlining all pedagogical components within courses and programs toward goals defined by demands of the next placement, linkage to workplace opportunities and requirements for good citizenship.

\section{Design}

The initial goal of the educational design process is to identify transformational endpoint competencies that satisfy expectations. Those expectations could be to match pre-specified outcome competencies such as may be supplied by accreditors and professional bodies or to define unique competencies that will distinguish each program of study from competitors.

Identifying, ordering, and empirically validating desired endpoint outcomes with acceptable rigor requires the marshalling of transparent processes, application of explicit techniques, and the full involvement of stakeholders. This process can involve a handful of individuals or a nation-wide community of practice. Outcome definition is a foundational activity that not only informs downstream teaching, learning, and assessment but also details the specifics of program or course outputs (competencies of graduates) thus establishing the reputation of the courses, programs, and institutions involved.

Pragmatic sub-outcomes, transition goals, and stage objectives must then be developed that will flexibly support learners reaching the endpoint goals. Program design techniques should be chosen that suit the situation at hand and that match the development of goals, outcomes, and objectives appropriate to the learners, the school setting, the expectations for the next learner placement, and eventually the target workplace market. This process should be supported by curriculum designers and educational developers who can break down the competencies into their learning components (Brown, 1994).

CBE has its roots in methods for critically examining work practices to improve work efficiency (Taylor, 1911). It follows that opportunities should be taken in all CBE educational design phases to identify and reduce or eliminate ineffective structures, practices, and expectations that may have been historically justified but are now impeding the efficiency of student learning. These structural impediments abound and are entrenched in social and commercial expectations: degree programs have minimum course requirements, and field experiences have time constraints and work obligations. In fully operationalized CBE, students who can demonstrate competencies in much less time than expected should not be paying tuition nor providing unpaid service for the same length of time as others in their cohort who may need more time to demonstrate the required competence. Most higher and professional education structures and work placements are presently illequipped to respond to these needs for seamless flexibility.

The CBE design phase requires effective negotiation and management to produce useful results and adequately serve the multiple stakeholders and unaligned purposes. Successful implementation will require design phases that explicitly include 
elements of situational analysis, consensus building, common language creation, demarcation of scopes of practice, and responsibility (Hodges, 2012). Designers must also acknowledge the limitations of $\mathrm{CBE}$ and plan explicit mitigations.

Regardless of the source of the competence definitions or the general educational plan, each program and educational unit, indeed, each participant must be actively involved in designing how desired competencies will be (or can be) attained within the complex local realities of teaching, learning, and practice.

\section{Teaching}

CBE, if well implemented, provides a framework for faculty and students to become true partners in the educational enterprise. CBE design identifies and structures minimally necessary learning outcomes connecting the classroom, lab, and experiential placement to requirements of the next level training and to real-life practice. Teaching with $\mathrm{CBE}$ requires understanding this learning structure as well as the knowledge and skill to flexibly adapt it to the needs of each individual learner. Lesson or experience planning in CBE is informed by well-written and well-organized course outcomes and objectives. It also requires a thorough understanding of the competence components to be developed, as well as the instructional activities, pedagogies, and assessments most likely to encourage that development.

When used effectively, CBE works as an advanced organizer and allows teaching (and learning) to focus beyond simple knowledge, skills, and attitude acquisition towards application, transfer, and impact assessment. When used ineffectively, CBE becomes a bureaucratic checklist that limits intellectual flexibility and creativity for both learners and teachers (Morcke et al., 2013) and will be incongruent with accepted teaching perspectives (Pratt, 1998).

Faculty must not only be professionally and personally engaged but also properly prepared and supported throughout a CBE implementation. It is wholly unreasonable to presume that faculty will be able to effectively teach and assess using CBE by simple extrapolation from their previous, likely more didactic, teaching or learning experiences. This is particularly true for sessional faculty and site-based faculty without academic appointments. With the right support, CBE need not mean more faculty work; its incorporation should be motivated by the potential of CBE to improve learning, assessment, courses, and programs.

Faculty may require help moving from teacher-centric to learning-centric practices. Preparation and support must extend faculty capabilities to bring in other pedagogical approaches (pragmatism, interpretivism) as required to moderate CBE limitations. It must also assist faculty to effectively participate in the assessment requirements of CBE, which are qualitatively and quantitatively different than common experience. Assessment concerns in $\mathrm{CBE}$ are addressed more fully later in this essay.

\section{Learning}

Even though CBE describes what "learning" is to occur versus the more traditional, what "teaching" is to occur, very little attention has been directed towards how to learn efficiently with CBE. This default puts students into a passive learning role and reduces the learning experience to checking off components that will result in a high or passing grade.

The concept of CBE designs pedagogical features to efficiently move learners toward the defined endpoint competencies. This should put learners at the centre of the educational enterprise, not the course structure, not the teaching or service schedules. If $\mathrm{CBE}$ is not well implemented, these legacy structures will remain, and constrain many learners. In response, learners must take responsibility to understand and optimize their learning experiences, much as successful students have done historically with other educational paradigms.

As a start, learners must develop an understanding of the strengths and limitations of CBE: why it is being used, and how it is being deployed in their situation. Learners must recognize how the CBE structure, as locally implemented, will affect their development and master a range of 
ameliorating strategies to optimize their success both in the current experience, in the next level, and eventually in real work settings. Students must learn how to use CBE to inform and organize studying, to complete activities, and to prepare for, and incorporate, assessments in the classroom, lab, and experiential settings. Ideally, the faculty will see themselves as aligned with the students in achieving these optimized learning strategies. If not, $\mathrm{CBE}$ can reduce learners to objects of assessment and accountability.

CBE can outline expected content and competence performance reasonably well, but the structure is challenged to communicate the holistic components of competence that include tacit attributes, attitudes, and complex coordination. As a principal defense, learners should leverage and connect learning opportunities outside the formal defined pedagogical space. Education is vastly aided by a host of informal educators, some of whom are prominent and identifiable in the field placements or workplaces: other professional workers, support and administrative personnel, other learners and clients. Recognizing and engaging these resources is a benefit to students trying to navigate and optimize attainment of both behavioural and tacit competencies. These informal educators will be more diverse than the designated faculty and not likely marked nor acknowledged for their true influence. Their legitimate involvement will contribute to the learner's developing sense of community, comradery, and trust, all hallmarks of responsibility, a commonly defined outcome competency.

\section{Administering CBE}

CBE itemizes and defines learning outcomes to support planning for learning and the structure for learning assessment. These defined outcome competencies also express the standards for instruction, performance, and grade assignment. As such, CBE documents the contract between the educational institution and the student. Failure to provide the stated instruction or comply with the specified standards has resulted in successful legal action by disgruntled students (The Canadian Press, 2012). Therefore, administrators should attend to the development and use of these CBE descriptive documents.

Training for, and joint monitoring of, $\mathrm{CBE}$ documentation will be helpful for both administrators and faculty as they may not appreciate the full consequence of not complying with these administrative components. This supportive oversight is challenging whether the administrator is a member of the particular discipline or not and may be perceived as contrary to individual notions of academic freedom. The administrative objective here is to build partnerships that support CBE implementation. That will include faculty and learners as prime stakeholders but also extend more broadly to include the sources of the endpoint competencies, and administrators in the next phase placements all the way to real life work placements.

Some components of CBE are best managed and monitored by administrators directly (liaison with worksites and employers) and others better devolved to faculty teams (innovative personalization in learning and assessment) or external experts (curricular evaluation of fit with program goals and workplace needs). Administrators must also audit their current organizational processes and procedures to continually seek improvement in alignment, efficiency, and effectiveness. We will return to these change-management challenges later in this essay.

\section{Assessment and Mastery Demonstration in CBE}

Assessment is the weakest link in CBE structured programs (Govaerts et al., 2007). Hampered by the limitations of the behaviourism at its root, rigidity in progression structures, misplaced faith in the universal fairness of raters, and even minimal similarity across rating situations, getting assessment right in CBE has been widely neglected (Blömeke et al., 2013).

CBE designers and participants must redesign assessment processes to better suit the 
variability of learners, teachers, assessors, and settings. Innovation and complex coordination are also needed to obtain adequate measures for the full breadth of competency requirements. At both national and local levels, critical examination is obligatory for current assessment practices, assumptions, intended, and unintended results. Some settings will have access to professional assessment expertise, others are advised to organize consulting or partnership arrangements to ensure that new or tweaked assessments are sufficiently rigorous, reliable, and valid in addition to being practical and useful to learners.

CBE can facilitate this examination of assessments within a course of study or across a program against established taxonomies of learning and next place or workplace requirements. It provides an organized structure of sequenced outcomes that allows for the creation, inspection, and integration of formative and summative assessments to ensure an intentional, integrated assessment design with learning useful feedback as opposed to simple student gating decisions. Programmatic assessment techniques should link and evolve assessments across the learning journey to achieve overarching program goals and outcomes that distinguish graduates as competent (Schuwirth \& Van der Vleuten, 2011). The clarity of these linkages facilitates a coordinated and efficient program of study and experience for the learner. Efficacy evaluation of this same linkage information can help justify program resources to internal administrators and external regulatory, accrediting, and advisory bodies.

Experiential placements have always been a central part of professional training and are increasingly utilized elsewhere in educational endeavours to provide context and authenticity for school-based learning. These work-site experiences are often the first occasion that learners are expected to function as part of a workplace team, appropriately contributing their acquired knowledge, skills, and attitudes over sustained, complex interactions in real time. Too often, however, these field involvements are unfocused, the learning outcomes unclear, and the learner's performance only informally assessed, if at all. Successful CBE implementation must correct these errors and optimize the opportunity for work relevant learning and work contextualized assessment.
Workplace assessments are complex because they must be applied across different contexts and are often administered by site staff, who may or may not have any assessment training or affiliation with the school. Building effective assessments for experiential placement means combining a variety of assessors with a variety of tools from both academic and organizational settings. These field assessment programs must be built to allow student progress to be monitored by faculty, the site, and the student throughout the placement. The goal is to provide maximal corrective information to learners as the experience unfolds as well as to support any pass/fail or graded decision to be made.

Once assessments are in place across a course or program, it is important to continually evaluate the overall assessment design as well as each individual component. Because competence assessment is so central to CBE methods, it is imperative that evidence be constantly acquired and considered about the quality of those assessments individually and collectively. Assessment quality is a requirement for any meaningful course or program evaluation. The central question is: can we prove that the experience/course/program produces graduates with all the requisite competencies?

\section{Learning Taxonomies Useful in CBE}

The contribution of learning taxonomies is the assistance they provide in organizing competency assessments to ensure that appropriate levels of complexity have been achieved at each stage (Morcke et al., 2013) and that the evaluation schemes are appropriate for the learning outcomes specified (Kraiger, Ford, \& Salas, 1993). Familiarity with learning taxonomies, and agreement on the taxonomies to be employed in local $\mathrm{CBE}$ implementation is essential across all participants. Functional taxonomies will help order the sequence of learning objectives towards desired endpoint competencies. Importantly they will remind designers, teachers, and learners of the learning and outcome breadth to be accomplished in any given 
sequence, course or program. Subsuming or ignoring the humanistic dimensions of competence is much harder if an effective learning taxonomy is agreed upon. However, not all taxonomies are equally well suited to $\mathrm{CBE}$, notably those including an affective domain.

Taxonomies of learning were initially created by a group of measurement specialists, led by Bloom (Bloom, Englehatt, Furst, Hill, \& Krathwohl, 1956) with the objective of creating a framework to categorize test bank items. The original taxonomy was created solely for assessment of the cognitive domain but subsequently expanded to the psychomotor and affective domains (Bloom, 1968). Within each domain, competencies are organized hierarchically from simple and concrete to complex and abstract.

Cognitive domain assessments originally tested knowledge at six nested levels of increasing complexity: knowledge, comprehension, application, analysis, synthesis, and evaluation (Bloom et al., 1956) subsequently revised to remember, understand, apply, analyse, evaluate, and create (Krathwohl, 2002). Cognitive domains are well suited to CBE structures as they atomize knowledge allowing discrete assessments. Standard parameters apply for test validity and reliability.

Equally adaptable to $\mathrm{CBE}$ are the psychomotor taxonomies. Bloom organizes psychomotor skills at seven nested difficulty levels: perception, readiness, guided response, habitual response, complex response, adaptation, and origination (Simpson, 1971). The validity of competence decisions based on skill testing can be improved by incorporating a variety of testing situations, contexts, and ranges of complexity (Shavelson, 2013). Building an assessment plan using a variety of approaches over time can confirm that the student is able to perform target skills competently.

Affective competency is difficult to operationalize with CBE. Bloom's Affective Taxonomy lists attitudes in five nested dimensions: receive, respond, value, organize values, and characterize by value (Krathwohl, Bloom, \& Masia,
1964). Attitudes are closer to internal personal dimensions including concepts of identity, personality, values, motivation, responsibility, and professionalism. Evidence of the existence or quality of these concepts is not directly visible and can only be inferred. Although assumed in CBE programs, making a connection between observed behaviour and underlying attitudes is even more fraught with potential observer bias than observing applied knowledge or skill. These biases can be reduced by triangulating observations across many observers, many occasions, and many sites.

Attitudinal assessment sequences should be developed to both observe and appropriately modify attitudes. An underdeveloped method to document growth in appropriate attitudes is through measures based in self-reflection. Regular opportunities for learner self-examination, reflection, reaction documentation, and self-report should be part of assessment designs for CBE. These efforts will be more effective for learning if feedback on the selfreflection can be supplied from within the relevant learning or work context during the timeframe of attachment there. Building an assessment plan using self-reflection must be carefully planned to keep the learner engaged in this challenging and often unfamiliar work.

There are learning taxonomies other than Bloom's. For example, the Structure of Observed Learning Outcomes (Biggs \& Collis, 1982) assesses the quality of learning as unstructured, multistructured, relational or extended abstract and Fink's (2003) taxonomy for significant learning blends cognitive and affective domains in a non-hierarchical framework. Bloom's Taxonomy, however, has been developed to explicitly include all three competence domains: cognitive, psychomotor, and affective. Employing this full range of learning domains is important if CBE implementation aspires to accomplish the complex of outcome competencies needed to function in civil society, to participate in social justice and sustainability, to bring critical thinking to everyday challenges, and yes, to perform well in workplaces. 


\section{Change Management Required for Implementing Successful CBE}

Successful CBE implementation requires a thorough reconsideration of many central aspects of the traditional education process. Educational design, teaching, learning, and assessment components have already been addressed. The full range of educational support systems must also be realigned. Commitment to $\mathrm{CBE}$ means changing the traditional organization of credits, courses, and semesters, which presents the opportunity to redesign the educational structure to better suit learners rather than institutions. At a minimum, ongoing negotiations, data sharing, and organizational adjustments must take place to optimize operations and results across the full range of players in a CBE system, including the faculty (both academic and site), the learners, administrators, other personnel and participants in the training placement sites and employers, accreditors, and regulators. Sustained effort must be invested to initiate, nurture, and deepen these relationships. It is from these partnerships that useful innovation will be suggested, supported, and implemented.

CBE counters the concept that school reputation ensures quality. It requires that faculty make their teaching and assessment explicit to the learner, colleagues, administrators, and others. Each part of the course plan is then subject to scrutiny and external alignment to the program curriculum, which, under CBE structures, is aligned to outcomes valued by next placement managers and eventually employers. These expectations will be new to many participants; successful introduction will require careful management.

Another area requiring proactive change management is the possibility, as $\mathrm{CBE}$ is implemented, of re-engineering the current timebased educational paradigms in favour of more flexibility for learners and employers. CBE provides direct measures of attained competence regardless of time spent, location, or method used to acquire the competence thus uncoupling traditional expectations of time in place (lecture, service, course) from mastery or competence. If everyone is simultaneously learning and applying their learning in workplaces, descriptors of full-time versus part-time learners will no longer be meaningful nor useful to learners, teachers, schools or work sites. Flexibility in educational structures requires new concepts and systems for recruitment, admissions, financial aid, learner tracking, monitoring faculty-student interactions, transcripts, and awards processes.

Personalized learning is a step further in implementing $\mathrm{CBE}$, and another change management challenge. Truly individualized learning plans must be routinely designed, adjusted, and delivered to fully realize the potential for learning efficiency within CBE structures. Prior learning assessment recognizes the knowledge and skills already possessed by a learner and structures subsequent learning to minimize the amount of time spent on areas previously mastered. Adaptive, individualized, and flexible learning programs support learners at any stage of development and are essential to attracting mature, mobile learners, particularly those already in or acutely sought by the workplace.

Information access to support learning has and will continue to change massively, presenting more change management issues within CBE. Content is now available on demand anywhere in the world through easily updated open access textbooks, videos, and other electronic educational resources. Real-time, multi-media, multi-perspective data recordings support new ways of learning, monitoring, and demonstrating competence. CBE designers and participants must regularly review and adapt the range of new technologies developed both within schools and by commercial vendors to facilitate teaching, learning, and assessment.

Another area for continued change management in $\mathrm{CBE}$ is the growing range of experiential learning, work-integrated learning, co-op education, credits for prior learning, and other realworld experiences. This field orientation is rapidly expanding in higher education due to increasing demands for work-ready graduates with demonstrable endpoint competencies. All these practical experiences must be assessed fairly, and effectively integrated into the academic curriculum. CBE can 
provide a scaffold to articulate these alignments, but they must be continually negotiated and adjusted across program specifications, learning sites, teachers, learners, and assessors to follow the evolving competencies needed in the workplace. Monitoring workplace change places CBE participants in a unique position to scrutinize the evolution of competence requirements and thus maintain the relevance of their program offerings. Changing work environments highlight needs for updating knowledge, skills, and attitudes among people already employed in those settings. These data are critical to the maintenance of competence and career advancement programs presenting a dynamic linkage and relevance opportunity for higher education and professional preparation institutions.

One of the biggest challenges in $\mathrm{CBE}$ implementation is to manage expectations among senior leaders, both educational and regulatory. Adopting a CBE approach does not happen by fiat. Actualizing the rhetoric of $\mathrm{CBE}$ requires a lot of intricate negotiation, management work, and planning, much of which is in new territory for most educational personnel, programs, and institutions. CBE implementation will require on-going innovation, trials, modification, and fine tuning. Because these are human systems, there is no guarantee that locally successful strategies can be exported. There continue to be significant challenges in developing site-specific CBE support systems, in implementing agreements and expectations for service work, in testing out processes, and in the array of other management problems that result from movement towards efficient competency-based learning.

How imminent are these expectations to actively manage change towards successful CBE implementation? As already outlined, medicine has mandated CBE implementation at undergraduate and graduate levels on a global basis. In the US, the Department of Education and related accreditors are slowly aligning their processes and expectations regarding CBE. Fein (2015) reported that 600 US colleges either were actively creating (or in design phases for) new competency-based education programs or already had a CBE program in place. Those numbers are a significant increase over the 52 institutions reporting CBE programs in 2014 (Fein, 2015). As the US Department of Education approves more CBE programs for federal financial aid, these numbers will continue to grow, as will the range of programs offered and the related competitive pressures on institutions, programs, and faculties to participate.

\section{Conclusion}

Regardless of conceptual and implementation limitations, CBE is directed towards the widelyshared goal of improving workplace performance by supplying graduates with relevant outcome competencies. Achieving this goal will require the pedagogical enterprise to evolve a knowledge and skill set not commonly part of the faculty or administrative preparation in higher education. CBE implementation will be significantly disruptive to most current educational programs, faculty, site personnel, learners, assessors, and administrators. Recognizing and addressing aversion to this radical departure from current operating procedures must first be resolved before a competency-based paradigm can be authentically realized. This evolution requires attention to improved techniques of self-awareness, personal goal setting, and self-appraisal for teachers, learners, and administrators in relation to demands of the locally deployed CBE structure. Participating in, and reflecting on, results from action research, teaching, and learning portfolios will be helpful as will training and support for time management, priority setting and negotiating performance criteria. Properly orchestrated, these techniques can help participants realize their shared goal to make CBE functional, efficient, and effective for their individual and collective purposes. This essay offers some guideposts for negotiating, supporting, and sustaining CBE so that it works optimally for all participants in the educational enterprise. 


\section{References}

Accreditation Council for Graduate Medical Education. (2016). ACGME Common Program Requirements (Effective July 1, 2016). VIEW ITEM

Albanese, M. A., Mejicano, G., Mullan, P., Kokotailo, P., \& Gruppen, L. (2008). Defining characteristics of educational competencies. Medical Education, 42(3), 248255. VIEW ITEM

Biggs, J. B., \& Collis, K. F. (1982). Evaluating the quality of learning: The SOLO taxonomy. New York, NY: Academic Press.

Blömeke, S., Zlatkin-Troitshcanskaia, O., Kuhn, C., \& Fege. J. (2013). Introduction. In S. Blömeke, O. Zlatkin-Troitshcanskaia, C. Kuhn \& J. Fege (Eds.), Modeling and measuring competencies in higher education: Tasks and challenges (pp. 1-10). Rotterdam, The Netherlands: Sense Publishers.

Bloom, B. S. (1968). Learning for mastery. Evaluation Comment, 1(2), 1-11. VIEW ITEM

Bloom, B. S., Engelhart, M. D., Furst, E. J., Hill, W. H., \& Krathwohl, D. R. (1956). Taxonomy of educational objectives: Handbook I, Cognitive domain. New York, NY: David McKay.

Brown, M. (1994). An introduction to the discourse on competency-based training (CBT). In J. W. Burk (ed.), Competency based education and training (pp. 1-17). London, UK: Falmer Press.

Calhoun, J. G., Wrobel, C. A., \& Finnegan, J. R. (2011). Current state in U.S. public health competency-based graduate education. Public Health Reviews, 33(1), 148-167. VIEW ITEM
Carraccio, C., Wolfsthal, S. D., Englander, R., Ferentz, K., \& Martin, C. (2002). Shifting paradigms: From Flexner to competencies. Academic Medicine, 77(5), 361-367. VIEW ITEM

Cooke, M., Irby, D. M., \& O’Brien, B. C. (2010). Educating physicians. A call for reform of medical school and residency. San Francisco, CA: JosseyBass.

Council for Aid to Education. (n.d.). CLA+ references. VIEW ITEM

Delaney, K. R., Carlson-Sabelli, L., Shephard, R., \& Ridge, A. (2011). Competency-based training to create the $21^{\text {st }}$ century mental health workforce: Strides, stumbles, and solutions. Archives of Psychiatric Nursing, 25(4), 225-234. VIEW ITEM

Fein, P. (2015, September 10). Keeping up with competency. Inside Higher Ed. VIEW ITEM

Fink, L.D (2003). Creating Significant Learning Experiences. San Francisco, CA: JosseyBass.

Fish, D. \& de Cossart, L. (2006). Thinking outside the (tick) box: Rescuing professionalism and professional judgement. Medical Education, 40(5), 403-404. VIEW ITEM

Frank. J. R., Mungroo, R., Ahmad, Y., Wang, M., De Rossi, S., \& Horsley, T. (2010). Toward a definition of competency-based education in medicine: A systematic review of published definitions. Medical Teacher, 32(8), 631-637. VIEW ITEM

Govaerts, M. J. B., van der Vleuten, C. P. M., Schuwirth, L. W. T., \& Muijtjens, A. M. M. (2007). Broadening perspectives on clinical performance assessment: Rethinking the nature of in-training assessment. Advances in Health Sciences Education, 12(2), 239-260. VIEW ITEM 
Hodges, B. D. (2010). A Tea-Steeping or i-Doc Model for medical education? Academic Medicine, 85(9), S34-S44. VIEW ITEM

Hodges, B. D. (2012). The shifting discourses of competence. In B. D. Hodges \& L. Lingard (Eds.), The question of competence (pp.14-41). Ithaca, NY: Cornell University Press.

Iobst, W. F., Sherbino, J., Cate, O. T., Richardson, D. L., Dath, D., Swing, S. R, Harris, P., ... Frank, J. R. (2010). Competency-based medical education in postgraduate medical education. Medical Teacher, 32(8), 651-656. VIEW ITEM

Kraiger, K., Ford, J. K., \& Salas, E. (1993). Application of cognitive, skill-based, and affective theories of learning outcomes to new methods of training evaluation. Journal of Applied Psychology, 78(2), 311-328. VIEW ITEM

Krathwohl, D. R. (2002). A revision of Bloom's Taxonomy: An overview. Theory into Practice, 41(4), 212-218. VIEW ITEM

Krathwohl, D. R., Bloom, B. S., \& Masia, B. B. (1964). Taxonomy of educational objectives: Handbook II, affective domain. New York: David McKay Co.

Long, D. M. (2000). Competency-based residency training: The next advance in graduate medical education. Academic Medicine, 75(12), 11781183. VIEW ITEM

Lum, G. (1999). Where's the competence in competence-based education and training? Journal of Philosophy of Education, 33(3), 403418. VIEW ITEM

Malone, K., \& Supri, S. (2012). A critical time for medical education: The perils of competencebased reform of the curriculum. Advances in Health Sciences Education, 17(2), 241-246. VIEW ITEM
McClelland, D. C. (1973). Testing for competence rather than for "intelligence." American Psychologist, 1-14. VIEW ITEM

Morcke, A. M., Dornan, T., \& Eika, B. (2013). Outcome (competency) based education: An exploration of its origins, theoretical basis, and empirical evidence. Advances in health Sciences Education, 18(4), 851-863. VIEW ITEM

Pratt, D. D. (1998). Five perspectives on teaching in adult and higher education. Malabar, FL: Krieger. VIEW ITEM

Schilling, J. F., \& Koetting, J. R. (2010). Underpinnings of competency-based education. Athletic Training Education Journal, 5(4), 165-169. VIEW ITEM

Schuwirth, L. W. T. \& Van der Vleuten, C. P. M. (2011). Programmatic assessment: From assessment of learning to assessment for learning. Medical Teacher, 33(6), 478-485. VIEW ITEM

Shavelson, R. J. (2013). An approach to testing and modeling competence. In S. Blömeke, O. Zlatkin-Troitshcanskaia, C. Kuhn \& J. Fege (Eds.), Modeling and measuring competencies in higher education: Tasks and challenges (pp. 2943). Rotterdam, The Netherlands: Sense Publishers.

Shippmann, J. S., Ash, R. A., Batjtsta, M., Carr, L., Eyd, L. D., Hesketh, B., ... Sanchez, J. I. (2000). The practice of competency modeling. Personnel Psychology, 53(3), 703-740. VIEW ITEM

Simpson, E. (1971). Educational objectives in the psychomotor domain. In M. B. Kapfer (ed.), Behavioral objectives in curriculum development (pp. 60-67). Englewood Cliffs, NJ: Educational Technology Publications.

Spady, W. G. (1994) Competency-based education: A bandwagon in search of a definition. In J. W. 
Burk (ed.), Competency Based Education and Training, pp. 21-31. London, UK: Falmer Press.

Talbot, M. (2004). Monkey see, monkey do: A critique of the competency model in graduate medical education. Medical Education, 38(6), 587-592. VIEW ITEM

Taylor, F. W. (1911). The principles of scientific management. New York, NY: Harpers \& Brothers. VIEW ITEM

Taylor, J. Irvine, F., Bradbury-Jones, C., \& McKenna, H. (2010). On the precipice of great things: The current state of UK nurse education. Nurse Education Today, 30(3), 239244. VIEW ITEM

The Canadian Press (2012, November, 21). George Brown loses lawsuit to foreign students. $C B C$ News Toronto. VIEW ITEM

The Conference Board of Canada. (2009, June, 11). Designing and delivering engaging competencybased inclusion training [Webinar]. VIEW ITEM

Tremblay, K., Lalancette, D., Roseveare, D. (2012). Assessment of higher education learning outcomes: Feasibility study report. Volume 1 - design and implementation. Retrieved from the Organisation for Economic Cooperation and Development website. VIEW ITEM

Touchie, C., \& ten Cate, O. (2016). The promise, perils, problems and progress of competencybased medical education. Medical Education, 50(1), 93-100. VIEW ITEM

Tuxworth, E. (1994). Competence-based education and training: Background and origins. In J.W. Burk (ed.), Competency Based Education and Training (pp. 109-123). London, UK: Falmer Press.
Tyler, R. W. (1949). Basic principles of curriculum and instruction. Chicago: The University of Chicago Press.

US Department of Education (n.d.). Competencybased learning or personalized learning. VIEW ITEM

\section{Biographies}

Lynn Curry earned a $\mathrm{PhD}$ in educational psychology from Stanford University followed by a career in higher and professional education concluding with a Rosenstadt Professorship at the Faculty of Medicine, University of Toronto. Lynn founded a consulting company, CurryCorp Inc. in 1990. The firm works to enhance education, social and health services through research, evaluation, social engineering, and facilitation of organizational change. Lynn's publications cover a range of topics including change management, continuing professional education, health care, higher education, learning style, measurement, public education and one award winning recipe in Good Housekeeping magazine.

Marcia Docherty is the Associate Dean of Health \& Human Services at Camosun College in Victoria BC. 
